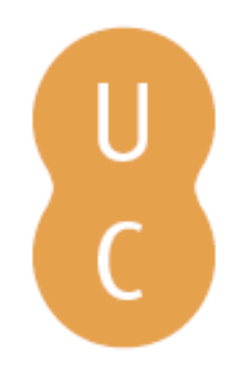

\title{
pompalina
}

\section{O golfe: lazer, turismo e sustentabilidade: reflexões sobre o caso português}

\author{
Autor(es): Gustavo, Nuno \\ Publicado por: Imprensa da Universidade de Coimbra \\ URL \\ persistente: \\ URI:http://hdl.handle.net/10316.2/37378 \\ DOI: $\quad$ DOI:http://dx.doi.org/10.14195/978-989-26-0754-2_17 \\ Accessed : $\quad$ 26-Apr-2023 13:10:20
}

A navegação consulta e descarregamento dos títulos inseridos nas Bibliotecas Digitais UC Digitalis, UC Pombalina e UC Impactum, pressupõem a aceitação plena e sem reservas dos Termos e Condições de Uso destas Bibliotecas Digitais, disponíveis em https://digitalis.uc.pt/pt-pt/termos.

Conforme exposto nos referidos Termos e Condições de Uso, o descarregamento de títulos de acesso restrito requer uma licença válida de autorização devendo o utilizador aceder ao(s) documento(s) a partir de um endereço de IP da instituição detentora da supramencionada licença.

Ao utilizador é apenas permitido o descarregamento para uso pessoal, pelo que o emprego do(s) título(s) descarregado(s) para outro fim, designadamente comercial, carece de autorização do respetivo autor ou editor da obra.

Na medida em que todas as obras da UC Digitalis se encontram protegidas pelo Código do Direito de Autor e Direitos Conexos e demais legislação aplicável, toda a cópia, parcial ou total, deste documento, nos casos em que é legalmente admitida, deverá conter ou fazer-se acompanhar por este aviso.

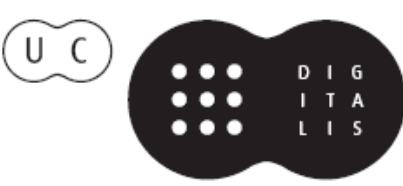


NUNO GUSTAVO

Escola Superior de Hotelaria e Turismo do Estoril

\section{O GOLFE - LAZER, TURISMO E SUSTENTABILIDAde: REFLEXón Sobre O CASO PORTUgués}

\section{Introdução}

O golfe é hoje reconhecido como uma prática desportiva intimamente associada a momentos de lazer, promovido e reconhecido pelos organismos institucionais de turismo como um produto estratégico, em particular nos países do sul da Europa, onde a natureza e caraterísticas do golfe permitem que este seja considerado com produto essencial na lógica de complementaridade face à restante oferta turística, estando esta alicerçada no dominante e sazonal produto turístico sol e mar (Hudson \& Hudson, 2010).

Apesar da fraca identificação cultural dos referidos países com o fenómeno do golfe, este apresenta-se como argumento de dinamização e desenvolvimento da atividade turística, realidade esta que se traduz numa crescente e cada vez mais significativa oferta de campos de golfe nos países em questão (Neirotti, 2005).

Recorrendo inicialmente a uma revisão da literatura sobre o âmbito e o desenvolvimento da prática do golfe enquanto fenómeno socioeconómico e, posteriormente, examinando um conjunto de dados estatísticos provenientes de diferentes fontes, o paper toma Portugal como estudo caso, discutindo a necessidade do binómio lazer-turismo para a sustentabilidade da atividade. A confrontação de dados estatísticos sobre a oferta e a procura do golfe em Portugal, em relação a outros países, nomeadamente aqueles onde o golfe faz parte da matriz cultural e sócio-identitária 
da população (ex: Suécia, Reino Unido, etc.), são base para uma reflexão sobre a sustentabilidade do golfe enquanto atividade económica e social.

Considerando o atual estádio de desenvolvimento do golfe em Portugal, o qual se carateriza por uma oferta significativamente desenvolvida e por uma procura predominantemente proveniente da atividade turística, em particular dos mercados emissores associados, torna-se premente repensar o futuro desta prática, apontando possíveis estratégias de modo a garantir a sua sustentabilidade no âmbito económico-social.

\section{Golfe - da Identidade cultural ao Produto Turístico}

Independentemente do local ou dos locais onde começou a ser praticado, a realidade é que as origens do golfe estão, desde sempre, associadas à Escócia e ao Royal and Ancient club de St. Andrews, fundado em 1522 (Ceron-Anaya, 2010:343).

The origins of the game of golf have been the subject of numerous debates, but it was the Scots who created the concept that the game of golf starts with the ball situated at a point just above ground and ends with it disappearing below ground (Campbell, 1994). The first reference to the game in Scotland dates back to 1457 when the Scottish Parliament declared that golf was interfering with the defence of the realm practice of archery, declaring golf to be 'utterly cryit doun and nocht usit' (Brasch, 1972) (Hudson \& Hudson, 2010:6).

O Jogo foi conquistando notoriedade enquanto prática desportiva e social a partir de meados do século XVI, embora inicialmente muito limitado a classes sociais mais abastadas. No continente Europeu, assim como na Ásia, a prática de golfe expandiu-se, através das conquistas coloniais e dos emigrantes escoceses e ingleses, podendo afirmar-se que, no final do século XIX, era já um jogo conhecido ao nível mundial, exceto nos Estados Unidos América, onde viria a ganhar particular destaque e notoriedade apenas no século XX. 
Golf was well established around the world by 1885 although not in the USA, the country that was to refine and define it during the 20th century. John Reid is acknowledged to be the founding father of golf in the USA. Reid, a Scottish expatriate businessman, imported a few clubs and balls from Scotland and in 1888 set up a rudimentary three-hole golf course near to bis house in Yonkers, New York. The players of this first course formed themselves into a club called St Andrew's (its name copied from its famous Scottish predecessor - complete with an apostrophe to differentiate it) (Hudson \& Hudson, 2010:6).

Fundamental para o processo de universalização do golfe foi o estabelecimento de regras, considerando as diferentes variantes que estiveram na origem desta prática. Mais uma vez, St. Andrews fica intimamente associada a este jogo, pelo fato de ter assumido a responsabilidade de definir as regras do golfe (Readman, 2003).

Hoje o golfe é uma prática desportiva e de lazer global: "and golf is now global; it's played in almost every kind of environment. A desert course in Arizona is totally unlike new courses cut through the rainforest in Malaysia to satisfy the demand of Japanese hospitality tourism. Urban courses surrounded by golfing communities evoke different impressions from golf resorts isolated amongst wetlands" (Perkins, 201:314).

O golfe é praticado em circuitos previamente definidos os quais, face à natureza e caraterísticas do jogo, distinguem-se pela sua área e enquadramento paisagístico, elemento fundamental na atração e condição de opção dos jogadores de golfe e/ou turistas. Conforme "Standeven and De Knop (1999:60), 'the experience of place is a key component of the sport tourism experience'. Not only does the separate sphere of tourism involve people being attracted to destinations with distinctive characteristics and qualities, but sport also requires specific spatially located resources" (Bull, 2005:25).

Na sua versão oficial, um campo de golfe tem dezoito buracos (num total de cerca de 6 quilómetros em linha reta), os quais se distinguem em diferentes zonas de jogo, nomeadamente tee, fairway, rough e green, as quais são alternadas com diferentes obstáculos, como por exemplo lagos, bunkers (poços de areia) ou árvores, conferindo a cada buraco em parti- 
cular e a cada campo no seu global uma geometria própria. "The diverse scenery in which golf is played not only forms a perceptual backdrop to the round but also affets on the design of the course" (Perkins, 2010:314). Deste modo a singularidade de um campo de golfe decorre, por um lado do seu referido enquadramento cénico e por outro da opção arquitetónica traduzida na organização dos diferentes elementos do jogo em articulação com os obstáculos naturais e artificias.

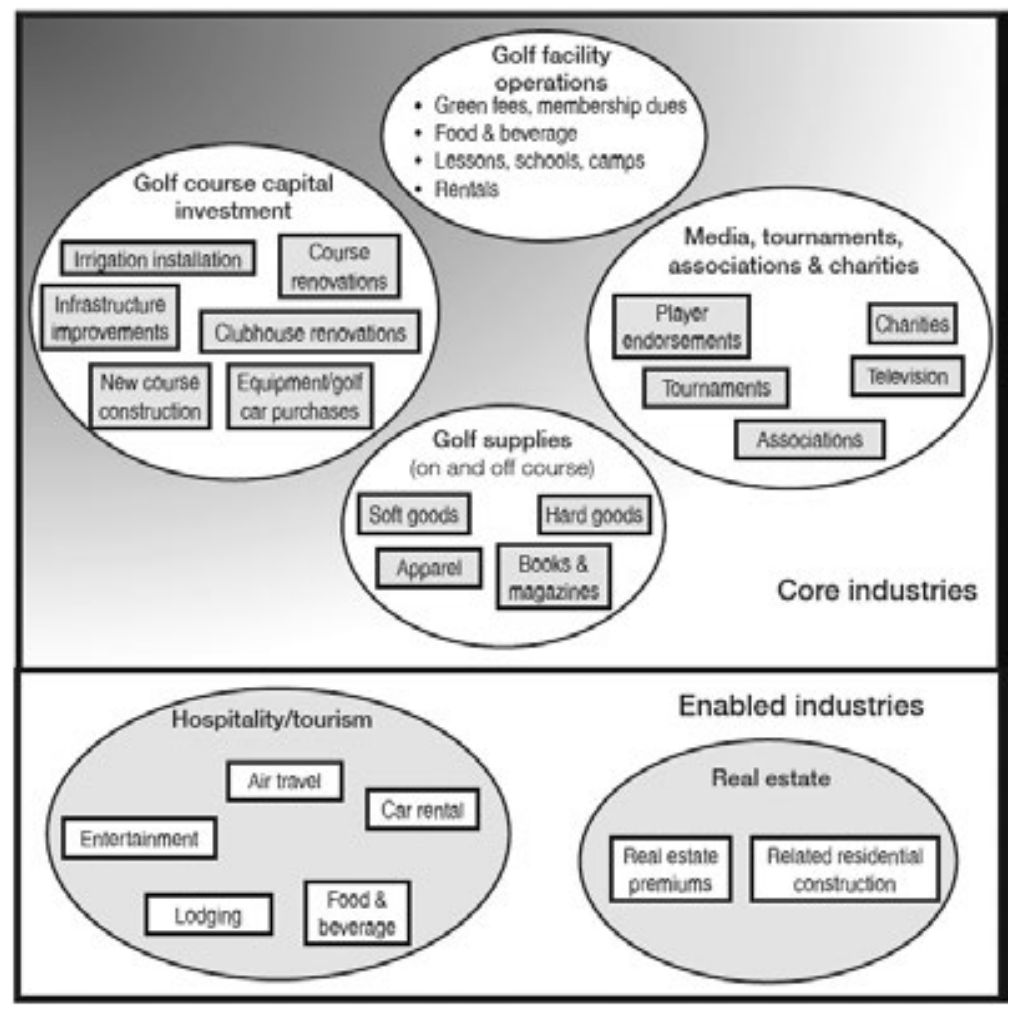

FIgura 1 - Valor Económico do Golfe

Fonte: KPMG 2008a, SRI International 2008 in Hudson \& Hudson, 2010:11

Face à natureza e caraterísticas do jogo, a construção de um campo de golfe implica um investimento avultado, envolvendo qualitativamente e quantitativamente um número significativo de recursos, situação que se traduz num conjunto alargado de efeitos diretos, indiretos e induzidos ao nível da atividade económica. Por outro lado, um campo de golfe, contra- 
riamente a outras infra-estruturas de lazer e turismo como por exemplo um ginásio ou um campo de golfe, é um recurso natural, pelo que a sua manutenção é exigente e obrigatoriamente diária, haja ou não haja clientes.

Nos países onde o golfe se assume como um desporto com relevância nacional, o investimento é muitas vezes suportado por capitais públicos, criando uma oferta de idêntica condição e garantido um acesso singular e livre a esta prática desportiva de lazer.

Já nos países onde o número de praticantes não é muito significativo, o investimento é, regra geral, potenciado e suportado por projetos privados, os quais são invariavelmente alicerçados num conjunto de atividades satélites, entre as quais assumem particular destaque a imobiliária e o turismo. Atente-se no referido contexto ao significativo incremento verificado nas últimas décadas nos países da Europa Ocidental:

"most of the impact of the golf industry in Portugal, Spain, France and Italy reflects golf enthusiasts travelling there for golf holidays and their purchase of holiday homes built as part of golf communities and golf resorts" (Hudson \& Hudson, 2010:10).

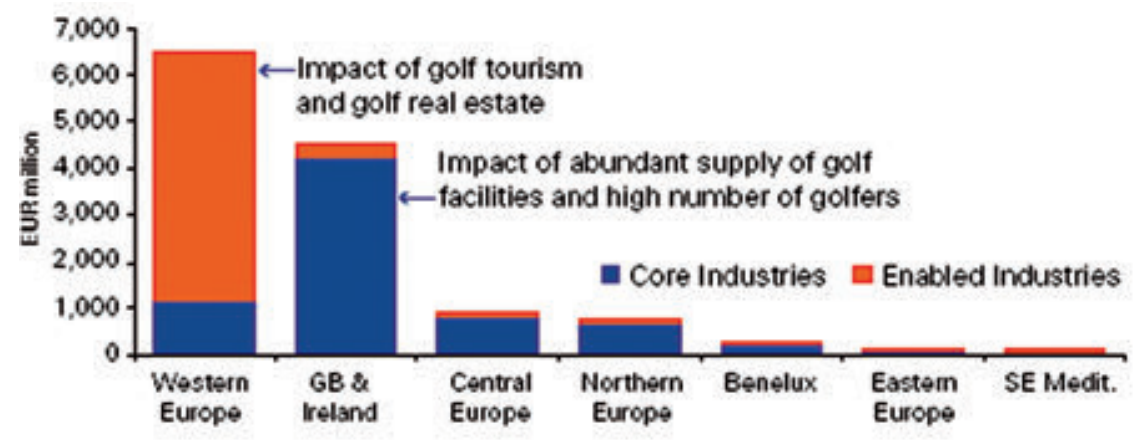

FIgura 2 - Contributo do Golfe na Europa para o Produto Interno Bruto, por Cluster, em 2006, por Sub-Região Fonte: KPMG \& Oxford Economics in KPMG, 2008

A relação entre o golfe e o turismo é hoje evidente, traduzido num segmento de mercado de caraterísticas particulares, cujo acesso está limi- 
tado aos titulares da condição de golfistas. Aliás, esta condição é comum a todos os campos privados, onde o acesso é apenas autorizado as titulares de handicap válido, situação que implica a federação do jogador.

Não obstante a referida situação, o número de praticantes à escala global tem registado um crescimento significativo, estimando-se que só na Europa o Golfe motive mais de um milhão de viagens por ano, valor este que, expetavelmente, deve duplicar até 2015 (MEI, 2007).

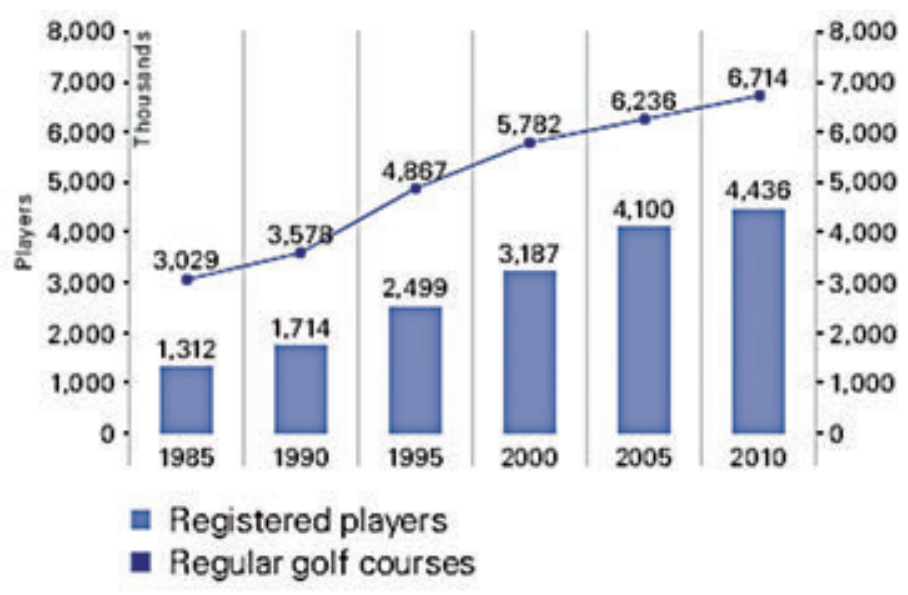

Saurce: European Golf Associasion (EGA) with KPMG elabovation

Note: we have only considered atfilated plyers and regular goll couses in the above chart

FiguRa 3 - Número de Jogadores Federados na Europa Fonte: KPMG, 2011:1

Para a afirmação de um destino turístico de golfe torna-se ainda crucial, a par do investimento privado e das necessárias condições climatéricas, a excelência cénica dos campos de golfe, bem como a diversidade qualitativa e quantitativa dos mesmos. "Golf has been systematically imported into many bot climate destinations as a tourism development strategy in recent years (Priestley, 1995; Bartoluci E_Cavlek, 2000)" (Higham \& Hinch, 2009:179).

Tal decorre da natureza e espírito do jogo, na medida em que o desafio se coloca essencialmente ao nível da relação/interação jogador/campo, apesar de ser preferencialmente jogado em grupo. Quanto maior for o 
número de campos de golfe, maior será a capacidade de atração e fixação de golfistas, já que durante a sua estada, o golfista pretende jogar em vários campos diferentes, ainda que permaneça no mesmo território e sempre no mesmo meio de alojamento. Do ponto de vista da comercialização, os "package" oferecidos pelos principais operadores com presença neste segmento (refira-se no contexto europeu por exemplo a Golf Plaisir ou a Easton Golf) oferecem verdadeiras experiências aos golfistas, os quais integram os campos de golfe (pacotes turísticos de $7 \& 5$ - sete noites e cinco green fees - ou $3 \& 2$ - três noites e dois green fees -, para além do voo, transfers, e aulas de golfe) do mesmo modo que os generalistas integram os diferentes tipos de recursos naturais e culturais de uma região.

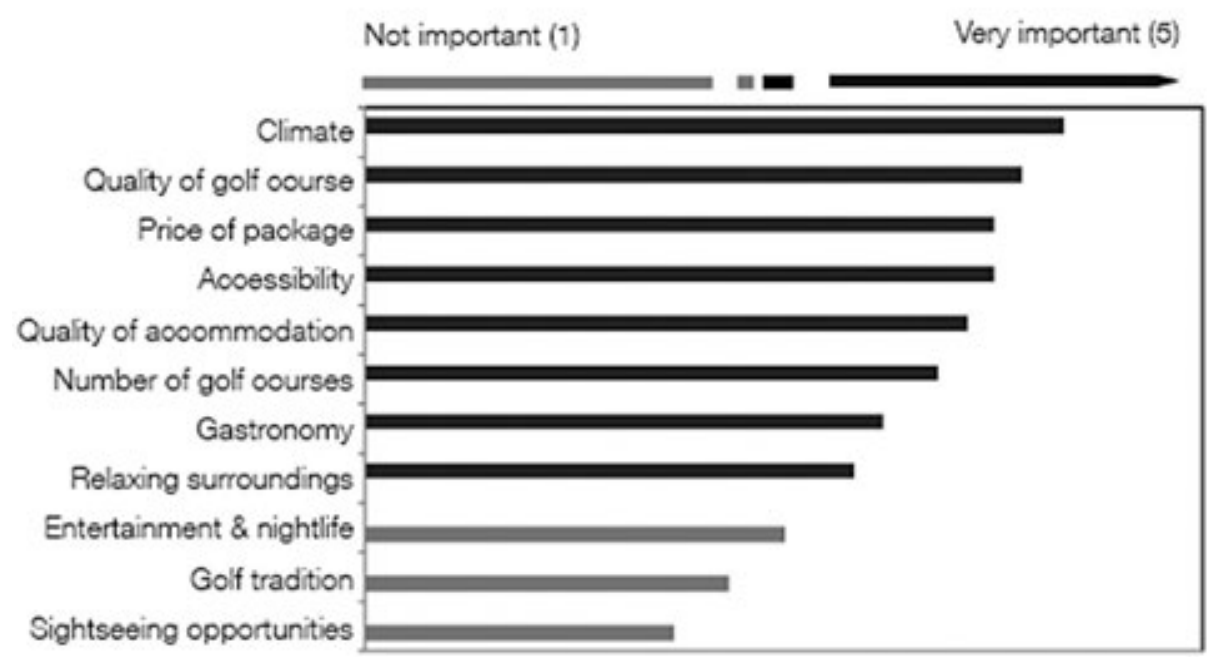

Figura 4 - Fatores de Escolha do Destino na ótica do Golfista Fonte: KPMG, 2008 in Hudson \& Hudson, 2010:41

Pelas suas caraterísticas únicas, o golfe vale, não só enquanto produto turístico, diversificando a oferta de um destino, como é ainda um produto relevante no sentido de contribuir para a atenuação do fenómeno sazonalidade em consonância com a restante oferta turística. "[T]he relationship between sport and tourism seasons can be actively influenced with desti- 
nation management goals in mind. Thus changes to the sport product mix, the use of sports events and the development of niche sport tourism markets are among some of the responses that destination organizations may pursue in an attempt to manage seasonal travel flows" (Higham, 2009:157). O potencial de integração com outros produtos turísticos, nomeadamente como o produto "Sol e Mar" confere ao golfe uma qualidade adicional de projeção e afirmação (Readman, 2003).

Este fato torna-se particularmente relevante, considerando que o desenvolvimento das práticas turísticas tem sido consolidado, quer pela via quantitativa, quer pela via qualitativa. Atente-se que em 1950 os cinco principais destinos turísticos mundiais representavam uma quota de $71 \%$ de todas as chegadas internacionais de turistas e, atualmente, esse valor não supera os $40 \%$, para além de incluir destinos de todos os continentes, não se circunscrevendo o fenómeno turístico apenas ao mundo ocidental (OMT; vários anos).

Perante este cenário, marcado por uma procura turística não só cada vez mais significativa e heterogénea, mas também mais experiente e exigente, torna-se premente para os destinos turísticos procurarem novos modelos estratégicos de competição e, inerentemente, novos fatores de diferenciação. O desafio não se limita a atrair, mas, também, e essencialmente, a fidelizar novos públicos. Até há algum tempo atrás, a singularidade patrimonial de um destino era fator suficiente de atração, assentando o seu modelo de competição na valorização desse património, através do desenvolvimento e capacitação da sua componente secundária (acessibilidades, infraestruturas de apoio, alojamento, etc.). Atualmente, essa condição, per se, tem-se revelado insuficiente, estabelecendo-se como uma mera premissa de um novo ambiente competitivo entre destinos.

Num mundo cada vez mais globalizado, onde por força do desenvolvimento tecnológico todos os lugares estão à distância de um clique ou de umas insignificantes horas de voo, definem-se novos paradigmas e fatores de competição sustentáveis. Neste cenário, a sustentabilidade e a diferenciação dos destinos turísticos tornam-se assuntos centrais, face a um mercado turístico cada vez mais maduro e global. A diversificação e competitividade dos produtos turísticos são vetores de desenvolvimento 
centrais na reinvenção da oferta, no sentido de conferirem aos destinos novos argumentos de competição e garantirem um mix de oferta que atenue, tanto quanto possível, as adversidades associadas à crescente competição global (Knowles et al., 2004).

\section{O Golfe - O Caso Português}

No panorama nacional o golfe assume uma condição relevante. Esta realidade traduz-se, não pela dimensão da procura interna, considerando que Portugal conta apenas com 15.000 jogadores federados, mas também pelo lado da oferta. Atualmente Portugal dispõe de uma oferta singular (cerca de 80 campos de golfe), considerando a sua dimensão territorial.

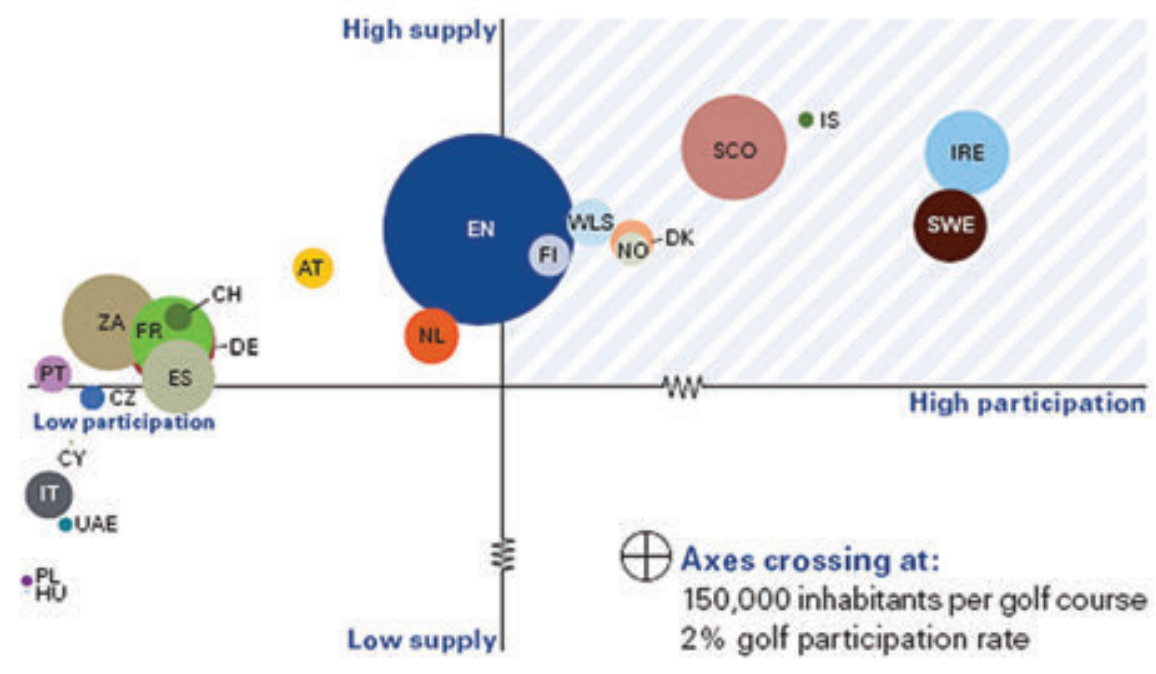

Figura 5 - Relação Oferta Procura de Golfe Fonte: KPMG, 2011:2

Esta realidade decorre essencialmente de dois vetores dinamizadores: o turismo e o imobiliário. Face à sua condição predominante de turismo sol e mar, Portugal encontrou no golfe um produto de elevado potencial. 
Considerando a natureza sazonal do turismo em Portugal, muito alavancada pelo Sol e Mar, com destaque para os meses de Verão, o golfe foi entendido e dinamizado com o produto atenuador desta assimetria, dado que a sua época alta está associada no mercado nacional aos meses de Março, Abril e Maio e Setembro, Outubro e Novembro, com destaque para os mercados emissores do Norte da Europa (Reino Unido e Escandinávia). Por outro lado, o argumento do campo de golfe, no contexto do mercado imobiliário em geral, e no caso particular do turismo residencial, foi utilizado como fator diferenciador de venda.

Esta realidade contribuiu decisivamente para que Portugal registe atualmente um desequilíbrio crónico, o qual é caraterístico de vários países do Sul da Europa os quais, por um lado, são por excelência recetores de turistas internacionais e, por outro, não têm esta como uma prática própria da sua matriz identitária cultural e desportiva.

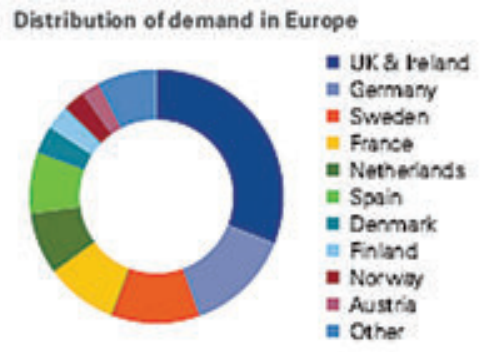

Distribution of supply in Europe

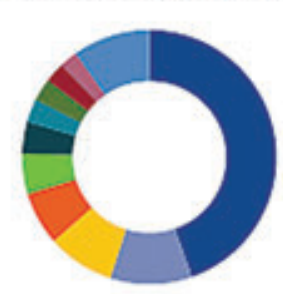

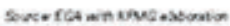

- UK 3 reland

in Germary

il France

n Sweden

in Spoin

a waly

n Denmark

" Netheriands

n Norway

E Austria

n Caher

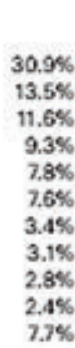

$30.9 \%$
$13.5 \%$
$11.6 \%$
$9.3 \%$
$7.8 \%$
$7.6 \%$
$3.4 \%$
$3.1 \%$
$2.8 \%$
$2.4 \%$
$7.7 \%$

Market demand: Participation rate taffilated golfers ony)

nuste $=5 \%$

in developed $1 \% \cdot 5 \%$
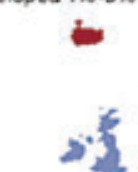

in growing $0.2 \% \cdot 1 \%$

infant $\leq 0.2 \%$

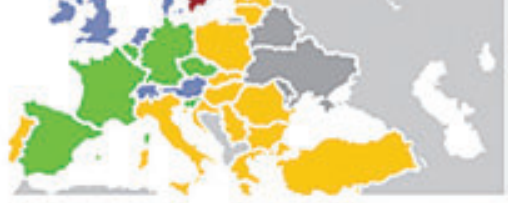

Market supply: Population per golf course

$44.6 \%$

$10.4 \%$

$8.5 \%$

$6.8 \%$

$5.1 \%$

$4.0 \%$

$3.0 \%$

$2.9 \%$

$2.6 \%$

$2.2 \%$

$9.8 \%$

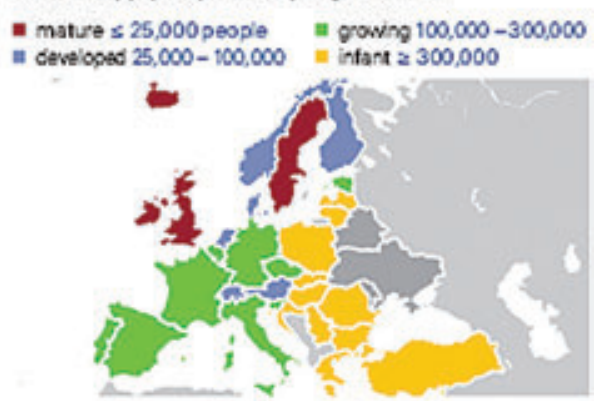

Figura 6 - Distribuição da Oferta e Procura de Golfe na Europa 
Esta é uma realidade particularmente significativa no caso português, dado que temos uma taxa de participação da população muito baixa $(0,136 \%)$, a par de uma oferta bastante desenvolvida. Este desequilíbrio quase crónico entre a oferta e a procura tem-se tornado particularmente relevante nos últimos anos, levando a uma descida acentuada do preço do green fee, como evidenciam os acordos celebrados entre os campos de golfe, a Federação Portuguesa de Golfe (FPG) e CNIG (Conselho Nacional da Indústria do Golfe), no sentido de oferecer tarifas promocionais aos seus associados.

Como podemos ainda constar no Quadro 1 , a realidade quase singular de Portugal, se não mesmo única, expressa-se também numa análise comparativa da dimensão territorial do país e da oferta de campos de Golfe por $\mathrm{Km}^{2}$. Neste cenário torna-se evidente que a prática de golfe em Portugal é um fenómeno quase de natureza turística, praticado por residentes em países como o Reino Unido ou a Escandinávia. Apesar dos seus benefícios para a saúde (em particular quando jogado a pé) e da dimensão da oferta nacional, o Golfe, enquanto prática desportiva e de lazer, é atualmente pouco expressivo em Portugal.

Quadro 1 - Taxa de Participação da População e Campos de Golfe por País

\begin{tabular}{|c|c|c|c|c|}
\hline Country & Playero & Couraes & $\begin{array}{r}\text { Partleipation } \\
\text { rate }\end{array}$ & $\begin{array}{r}\text { Population per } \\
\text { golf course }\end{array}$ \\
\hline UK \& Ireland & $1,369,448$ & 2.993 & $2.206 \%$ & 20.744 \\
\hline Germany & 599,328 & 700 & $0.728 \%$ & 117,614 \\
\hline Swoden & 512,407 & 456 & $5.656 \%$ & 19.868 \\
\hline France & 410,377 & 574 & $0.637 \%$ & 112,230 \\
\hline Netheriands & 344,000 & 192 & $2058 \%$ & 87,062 \\
\hline Spain & 338,160 & 345 & $0.034 \%$ & 117,464 \\
\hline Denmark. & 152,622 & 201 & $2.775 \%$ & 27,366 \\
\hline Fintand & 137,282 & 126 & $2.615 \%$ & 41,669 \\
\hline Norway & 125,160 & 174 & $2.686 \%$ & 26,785 \\
\hline Auscria & 104,475 & 151 & $1.272 \%$ & 54,373 \\
\hline italy & 100,317 & 260 & $0.173 \%$ & 216.083 \\
\hline Switzertand & 76,693 & 94 & $1.009 \%$ & 80,699 \\
\hline Belgium & 63,190 & 79 & $0.511 \%$ & 131,827 \\
\hline Catch Aep. & 46,331 & 82 & $0.464 \%$ & 124,635 \\
\hline
\end{tabular}

\begin{tabular}{|c|c|c|c|c|}
\hline Country & Playera & Courses & $\begin{array}{r}\text { Partielpation } \\
\text { rate } \\
\end{array}$ & $\begin{array}{r}\text { Population per } \\
\text { golf sourae }\end{array}$ \\
\hline Portugal & 14,545 & 84 & $0.136 \%$ & 127,475 \\
\hline stovents & 7,900 & 72 & 0.31945 & 107,141 \\
\hline Slovakia & 6.000 & 12 & $0.110 \%$ & 455,254 \\
\hline Turkey & 5,538 & 18 & $0.007 \%$ & $4,266,974$ \\
\hline Luxembourg & 4,111 & 6 & $0.836 \%$ & 81,903 \\
\hline Poland & 2.750 & 24 & $0.007 \%$ & $1,603,455$ \\
\hline Hungary & 2,500 & 13 & $0.026 \%$ & 701,969 \\
\hline Estonia & 1,956 & 7 & $0.150 \%$ & 185,624 \\
\hline Cyprus & 1,351 & 9 & $0.126 \%$ & 120,628 \\
\hline Greece & 1,335 & 7 & $0.012 \%$ & $1,533,918$ \\
\hline Latvia & 775 & 3 & $0.038 \%$ & 743,834 \\
\hline Romania & 581 & 4 & $0.002 \%$ & $6,663,866$ \\
\hline Croatia & 550 & 3 & $0.012 \%$ & $1,496,470$ \\
\hline Lithuanis & 430 & 5 & $0.012 \%$ & 711,036 \\
\hline Serbia & 300 & 1 & $0.004 \%$ & $7,334,936$ \\
\hline Bulgaria & 166 & 4 & $0.002 \%$ & $1,801,172$ \\
\hline Europe total & $4,436,085$ & 0,714 & $0.753 \%$ & 87,703 \\
\hline
\end{tabular}

Fonte: KPMG, 2011:4 
Apesar da evidência da situação, esta é uma realidade negligenciada em Portugal, como podemos verificar pela taxa de participação dos jovens jogadores europeus, na qual Portugal não ocupa qualquer lugar de relevo contrariamente à oferta de campos de golfe.

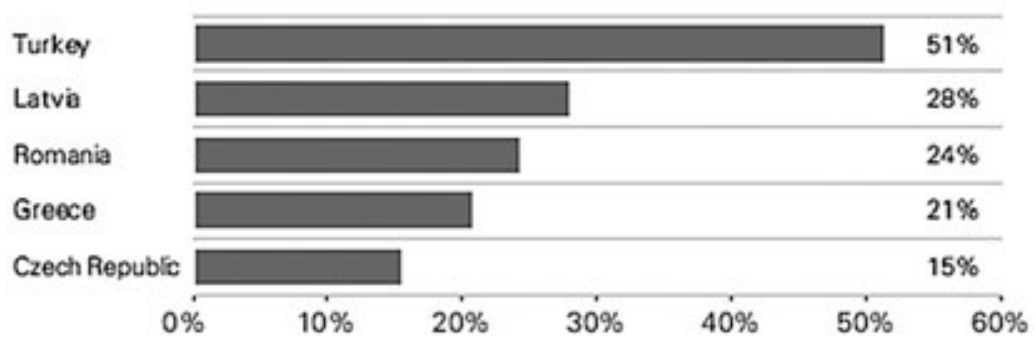

Source: EGA with KPMG elaboration

Figura 7 - Principais Países em termos de \% de jovens jogadores golfistas Fonte: KPMG, 2011:3

\section{Considerações Finais}

Num cenário turístico cada vez mais competitivo, a diversificação dos produtos e a aposta em nichos turísticos assumem um papel cada vez mais relevante.

Ao assentar na prática de uma modalidade desportiva que se destaca pelo desafio individual de superar os desafios de campo e pelo convívio e networking, o golfe assume-se como um verdadeiro motivo de viagem. Independentemente da sua condição de nicho ou de produto turístico, o golfe está cada vez mais presente, quer nos modelos de desenvolvimento dos destinos turísticos, atraindo cada vez mais diferentes protagonistas do turismo, sejam eles consumidores, sejam eles investidores.

O golfe é uma prática em clara ascensão, realidade esta, impulsionada, nomeadamente, por novos heróis do desporto internacional os quais despertaram a atenção dos média e dos patrocinadores, lançando na senda internacional um conjunto de eventos de singular espetro mediático. 
Ever since Tiger Woods first won the Masters' in 1997, golf has got sexier. No longer largely the preserve of the privileged, it's become a trendy sport with an appeal across generations, genders and cultures. The Ryder Cup is now watched on television by around a billion people worldwide. Compare that to the mere 260 million who watched the 2006 Soccer World Cup. TV has helped create golf icons across the globe with increasing tournament coverage and advertising endorsement (Hudson \& Hudson, 2010: 3)

\begin{tabular}{|c|c|c|c|}
\hline Perion & Sport & Country & $\begin{array}{l}\text { Total earnings } \\
\text { in } 2000\end{array}$ \\
\hline Ther Woods & Goll & usa & uso $90 \mathrm{sm}$ \\
\hline Roger Federer & Terris & Swerertand & USD $61.8 \mathrm{~m}$ \\
\hline Fal Mecketson & Colt & usa & USD $61.7 \mathrm{~m}$ \\
\hline Fogd Maymeuter in: & Bouing & USA & $450603 \mathrm{~m}$ \\
\hline LeGron lames & Bashectbell & USA & USO $45.8 \mathrm{~m}$ \\
\hline Lioret Messe & focoses & Argertins & USO $44 \pi$ \\
\hline Devid Eecktam & Foocteat & Gest Erean & USO $40.5 \mathrm{~m}$ \\
\hline Crationo Ronaido & Footeal & Portopy & USD $40 \mathrm{~m}$ \\
\hline Mansy Pacquiso & Beang & Arilppines & USO $38 \mathrm{~m}$ \\
\hline kheo Sueded & Ansectall & Apan & USD $3 \mathrm{r}$ \\
\hline
\end{tabular}

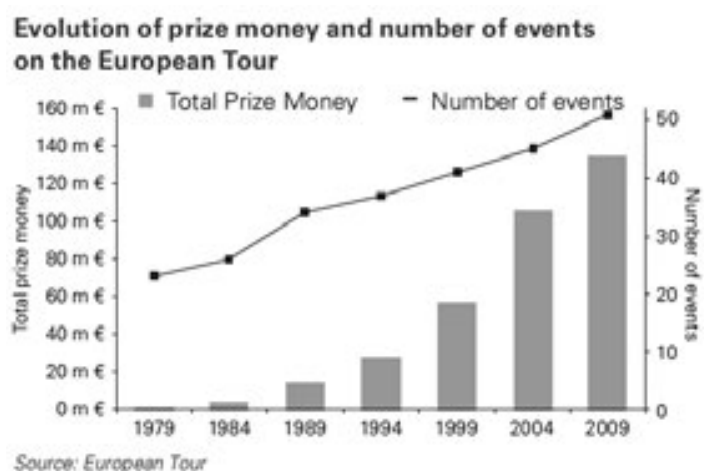

FIgURA 8 - Principais Atletas internacionais por Benefícios Totais e Eventos Evolução dos Eventos de Golfe e respetivo Prize Money

Fonte: KPMG, 2010: 7-11

O crescente número de praticantes a nível internacional, aliado ao fato de este ser um fenómeno cada vez mais turístico, fruto da possibilidade do turista gozar da opção de escolha do seu destino de viagem em função dos novos desafios de jogo oferecidos pelo clima e natureza de cada campo, confere a este produto um elevado potencial de crescimento, estimando-se que, só na Europa, o golfe seja capaz de motivar cerca de dois milhões de viagens em 2015 (MEI, 2007).

Todavia, pelas suas caraterísticas e virtudes, esta deverá ser uma prática não só turística mas essencialmente de lazer, condição esta, própria da sua génese. O desenvolvimento do golfe enquanto atividade turística será dificilmente sustentável, considerando o fato de esta ser no referido cenário uma prática acentuadamente sazonal. Face às necessidades económicas 
e financeiras do golfe, a sua sustentabilidade deve ser estrategicamente ponderada por referência ao mercado do lazer.

Nas referidas circunstâncias, o futuro do golfe em Portugal terá que ser necessária e urgentemente reequacionado, podendo o modelo de desenvolvimento sustentar-se nas seguintes e possíveis opções estratégicas:

- PORTUGAL AS A GOLF SPOT: o golfe como uma prática eminentemente turística: neste caso a oferta terá que ser necessariamente reequacionada, uma vez que a mesma é claramente excessiva para a dimensão do mercado turístico de golfe em Portugal.

Esta situação decorre do fato do mercado nacional contar apenas com cerca de 15.000 jogadores, dimensão de mercado esta que se torna manifestamente insuficiente para garantir a ocupação da atual oferta durante cerca de 6 meses do ano, já que os restantes 6 meses são preenchidos eminentemente por uma procura internacional. Esta procura internacional, em linha com a oferta de campos de golfe e com a demais oferta turística, tem particular expressão no Algarve e em Lisboa (incluindo a Costa do Estoril e a Costa Azul). O Algarve concentra $45,1 \%$ da oferta de campos de golfe nacional e Lisboa $27,4 \%$ (Turismo de Portugal, 2008).

Esta opção estratégica justifica-se ainda pelo fato do golfista internacional, durante a sua estadia, optar por jogar em diferentes campos, sendo por este fato crucial a concentração da oferta e o seu desenvolvimento em regiões específicas (Observatório do Turismo de Lisboa, 2010). Deste modo, a oferta de golfe em Portugal seria organizada, não numa lógica de destino, mas de Spots de golfe, com particular atenção para as regiões do Algarve e Lisboa (Costa do Estoril e Costa Azul).

Certo será que a presente opção implica uma redução significativa da atual oferta de campos de golfe, situação que acarreta a curto prazo um conjunto de impates negativos a diferentes níveis: económico, social e ambiental.

- PORTUGAL AS A GOLF DESTINATION: o golfe como uma prática eminentemente de lazer. Para além da dimensão turística identificada no cenário anterior, neste cenário o golfe tende a ser assumido como 
uma prática de lazer no universo cultural e desportivo português. Esta realidade exige a definição de um plano estratégico de desenvolvimento para a modalidade, quer em termos da procura, quer em termos da oferta, configurando-se o golfe como uma prática de lazer. Deste modo viabiliza-se a oferta atualmente existente e garante-se, na ótica do desenvolvimento da oferta, os pressupostos para Portugal se assumir como um destino de golfe competitivo e sustentável numa ótica económico-social.

O primeiro eixo específico de ação proposto - desenvolvimento da procura - deve ser realizado tendo como objetivo central a identificação cultural dos portugueses com o Golfe (Neirotti, 2005). Para tal, torna-se fundamental a definição de uma linha de ação visando a definição de um modelo formativo integrado de natureza público-privada. O envolvimento dos agentes privados através da facilitação e acesso aos recursos formativos (campos de golfe e infra-estruturas formativas associadas, profissionais de golfe, etc...) e a inclusão e dinamização do golfe nos planos de educação, são linhas fundamentais deste eixo de ação. Por outro lado, importa ainda desenvolver uma linha de ação em termos comunicacionais, com recurso a ações de natureza. A aposta deve centrar-se num plano promocional regular e não apenas por ações pontuais de mediatismo internacional.

Por outro lado, importa salientar no âmbito do referido plano de desenvolvimento estratégico nacional para o golfe, a necessidade de investimento público-privado no desenvolvimento de equipamentos e recursos para a prática do golfe, na medida em que, o "Golf is a technical sport requiring an extensive body of competencies before career opportunities can be fully exploited. Acquisition of such knowledge is often cost probibitive for members of minority groups, which subsequently excludes minorities from active participation and career exploration." (Fjelstul, et. al, 2011). Como a própria história do golfe demonstra, importa considerar a representação social do golfe, construída em torno da exclusividade das classes sociais, dos clubes e da etiqueta associada. "The frequency of rules regarding etiquette grew on a par with the increasing exclusion of the Scottish lower class from the sport. "The early history [of golf] does suggest that there 
was popular participation in the 18th century, [but] formalisation began to shift it toward being a middle-class preserve" (Lowerson, 1994a, p. 79) (Ceron-Anaya, 2010:344).

\section{Referências bibliográficas}

Buhalis, D. and Costa, C. (eds.) 2006, Tourism Business Frontiers - Consumers, products and industry. London: Elsevier.

Bull, C. 2005, Sport tourism destination resource analysis, in Higham, J. (Ed.) Sport Tourism Destinations - Issues, opportunities and analysis. Oxford: Elsevier Butterworth-Heinemann.

Ceron-Anaya, H. 2010, An Approach to the History of Golf: Business, Symbolic Capital, and Technologies of the Self, in Journal of Sport and Social Issues. 34(3), pp. 339-358.

FJelstul, J.; Jackson L. \& Tesone, D. 2011, Increasing Minority Golf Participation Through PGA Education Initiatives, in Sage Open. pp. 1-5.

Higham, J. \& Hinch, T. 2009, Introduction to sport tourism destination marketing and management, in Higham, J. (Ed.) Sport Tourism Destinations - Issues, opportunities and analysis. Oxford: Elsevier Butterworth-Heinemann.

Higham, J. \& Hinch, T. 2009, Sport and Tourism - Globalization, Mobility and Identity. Oxford:Butterworth-Heinemann.

Hudson, S. \& Hudson, L. 2010, Golf Tourism. Oxford: Goodfellow Publishers Limited. Hudson, S. (Ed.) 2002, Sport and Adventure Tourism. Oxford: The Haworth Hospitality Knowles, T; Diamantis, D, and El-Mouhabi 2004, The Globalization of Tourism \& Hospitality. London: Thomson.

KPMG 2008, The economic value of golf to Europe [online] http://www. egcoa.eu/bestanden/pics/The\%20Economic\%20Value\%20of\%20Golf\%20to\%20 Europe_28082009\%20(2).pdf

KPMG 2010, The Business of Profissional Tournament Golf [online] http://www. kpmg.com/DK/da/nyheder-og-indsigt/nyhedsbreve-og-publikationer/publikationer/advisory/generelle-publikationer/Documents/The\%20Business\%20of\%20 Professional\%20Golf.pdf 
KPMG 2011, Golf participation in Europe. [online] www.golfbusinesscommunity. com/.../golf_participation_in_europe_2010

MEI [Ministério da Economia e Inovação Portugal] (2007). Plano Estratégico Nacional do Turismo - para o desenvolvimento do turismo em Portugal. Lisboa: Turismo de Portugal.

Neirotti, L. 2005, Sport tourism markets, in Higham, J. (Ed.) Sport Tourism Destinations - Issues, opportunities and analysis. Oxford: Elsevier Butterworth-Heinemann.

Organização Mundial do Turismo [OMT] (2001). Tourism Visions 2020. Madrid: UNTWO.

Perkins, C. 2010, The Performance of Golf: Landscape, Place, and Practice in North West England, in Journal of Sport and Social Issues. 34(3), pp. 312-338. Readman, M. 2003, Golf Tourism, In Hudson, S. Sport and Adventure Tourism. London: Haworth Hospitality Press. 